\title{
Using social and physical variables to assess vulnerability of northwestern Montana lakes to illegal fish introductions
}

\author{
Niall G. Clancy • Samuel L. Bourret $\mathbb{D}$
}

Received: 17 October 2019/Revised: 19 May 2020/ Accepted: 25 May 2020/Published online: 31 May 2020

(C) The Author(s) 2020

\begin{abstract}
The spread of non-native fish species is a common problem in lakes and streams worldwide. Species that establish viable populations in a new environment can seriously deplete populations of native species and desired sportfishes. In some instances, extirpation of a native species has occurred. In western North America, the most common avenue by which non-native species invade new waterbodies is illegal stocking by anglers, aquaculturists, and others. Thus, preventing further illegal fish introductions is of the utmost importance for native aquatic species. Using data collected by state agency personnel from 1953 to 2015, we examined multiple social and physical variables to determine the factors that best explain which lakes in northwestern Montana had past illegal fish introductions. An equation using elevation, surrounding population, and fishing pressure was found to best fit the data. This equation was then used to calculate an index of the vulnerability of
\end{abstract}

Handling editor: Antti P. Eloranta

Electronic supplementary material The online version of this article (https://doi.org/10.1007/s10750-020-04312-z) contains supplementary material, which is available to authorized users.

N. G. Clancy · S. L. Bourret $(\square)$

Montana Fish, Wildlife \& Parks, 490 N. Meridian Rd.,

Kalispell, MT 59901, USA

e-mail: sbourret@mt.gov lakes within the region to future illegal fish introductions. The techniques used in this study have broad applicability that can be used in many regions with illegal fish introductions, and ultimately help to alleviate the problem.

Keywords Illegal introductions · Bucket biology · Invasive species $\cdot$ Social variables $\cdot$ Montana .

Coldwater lakes

\section{Introduction}

Invasive species are leading to declines in abundance and biodiversity of native fauna across many environments, creating irreversible global change (Sala et al., 2000; Simberloff et al., 2013). The human mediated spread of invasive species is exacerbated by other anthropogenic impacts on the landscape including habitat degradation and climate change, which make the ecological dynamics of invasion challenging and unpredictable phenomena (Engelkes \& Mills, 2011; Vindstad et al., 2013). This is especially prevalent in freshwaters where introductions of non-native species have led to the extirpation and, in some cases, extinction of many sympatric vertebrates (Vitule et al., 2009). One of the most cited case-studies of this phenomenon occurred in northwestern Montana's Flathead Lake where an agency effort to boost the food 
supply of sportfish populations through the addition of freshwater shrimp (Mysis relicta) in an upstream waterbody, resulted in a trophic cascade that caused virtual extirpation of a valuable fishery and had irreversible food web impacts (Spencer et al., 1991; Ellis et al., 2011).

Many introductions of freshwater species were historically conducted by governmental agencies and often aided by members of the public whose goals included supplementing sources of human sustenance and increasing recreational angling opportunity (Rahel \& Smith, 2018). But as fisheries management philosophies have changed in light of study on the impacts of invasive species and greater sustainability of wild fish populations (Vincent, 1987), stocking of natural waterbodies has become highly regulated. Today, illegal fish introductions by rogue anglers and aquaculturists are fast becoming the largest source of non-native fish species (Elvira \& Almodovar, 2001; Rahel, 2004; Leprieur et al., 2009). This is especially true in the northern and western regions of North America where illegal fish introductions have increased in areas with fewer species of native sportfishes (Johnson et al., 2009). Indeed, historically isolated headwaters with low diversity are more prone to biotic invasions relative to habitats with high aquatic endemism which can minimize the probability of successful establishment by invasive species in undisturbed habitats (Sala et al., 2000).

From 1961 to 2017, half of the documented illegal fish introductions in Wyoming involved the deliberate release of fish by the public, introducing 10 new species to the state (Rahel \& Smith, 2018). Such introductions can have devastating consequences for native fish populations as well as ecosystem functioning, and are difficult to control. The impacts of introduced freshwater fish to native species and biodiversity occur through predation, competition, hybridization, habitat modification, and transmission of disease (Gozlan, 2009). Through food web alteration, fish introductions can simplify biotic communities and lead to a loss of ecosystem resilience to other perturbations (Schindler, 1990; Folke et al., 2004). Moreover, once species become established in a waterbody, they are extremely difficult and expensive to remove, diverting resources from programs that benefit anglers, aquatic resources, and the environment (Johnson et al., 2009; Marr et al., 2010). For example, the illegal introduction of Lake Trout
(Salvelinus namaycush) into Yellowstone Lake in the late 1980's resulted in an average yearly abundance decline of $11 \%$ in native Yellowstone Cutthroat Trout (Oncorynchus clarkii bouvieri) from 1994 to 2004 (Gresswell, 2011). Subsequent mitigation efforts have cost millions of dollars in an attempt to suppress Lake Trout populations (Johnson et al., 2009).

Nearly all states in the US have adopted laws that regulate the importation, possession, and release of fish (Courtenay \& Robins, 1975). Still, illegal fish introductions have grown in prevalence, and those responsible are rarely caught. Indeed, a 2015 capture of illegally introduced Walleye (Sander vitreus) in Montana's Swan Lake was traced using otolith geochemical techniques to a reservoir 309 road kilometers away (Bourret \& Clancy, 2018). But despite substantial reward offers for information leading to a conviction, no suspects have yet been identified. Such introductions of warmwater species are especially concerning due to calls for caution in stocking Walleye and Northern Pike (Esox lucius), both apex predators (McMahon \& Bennett, 1996).

Unfortunately, new fish species continue to be illegally introduced and the number of aquatic ecosystems with an intact native species assemblage continues to decline. Thus, a fundamental question is what social and physical characteristics cause humans to illegally introduce new species. We hypothesized that a combination of social and physical attributes could be used to explain the prevalence of illegal fish introductions in the waterbodies of northwestern Montana. Further, we predicted this framework could be used to accurately assess the vulnerability of waterbodies to future illegal introductions. Using a novel database of illegal fish introductions collected from 1953 to 2015, our main objective in this study was to predict which waterbodies in northwestern Montana (Fig. 1) are at high risk of illegal fish introduction and should be prioritized for preventative signing, increased fish sampling frequency, educational outreach, and law enforcement patrols.

\section{Methods}

Located in the northwestern part of the state, Montana Fish, Wildlife \& Parks (MFWP) Region 1 ("Region 1 " from here on) is a $38,523 \mathrm{~km}^{2}$ area dominated by coldwater, oligotrophic waterbodies in a montane 


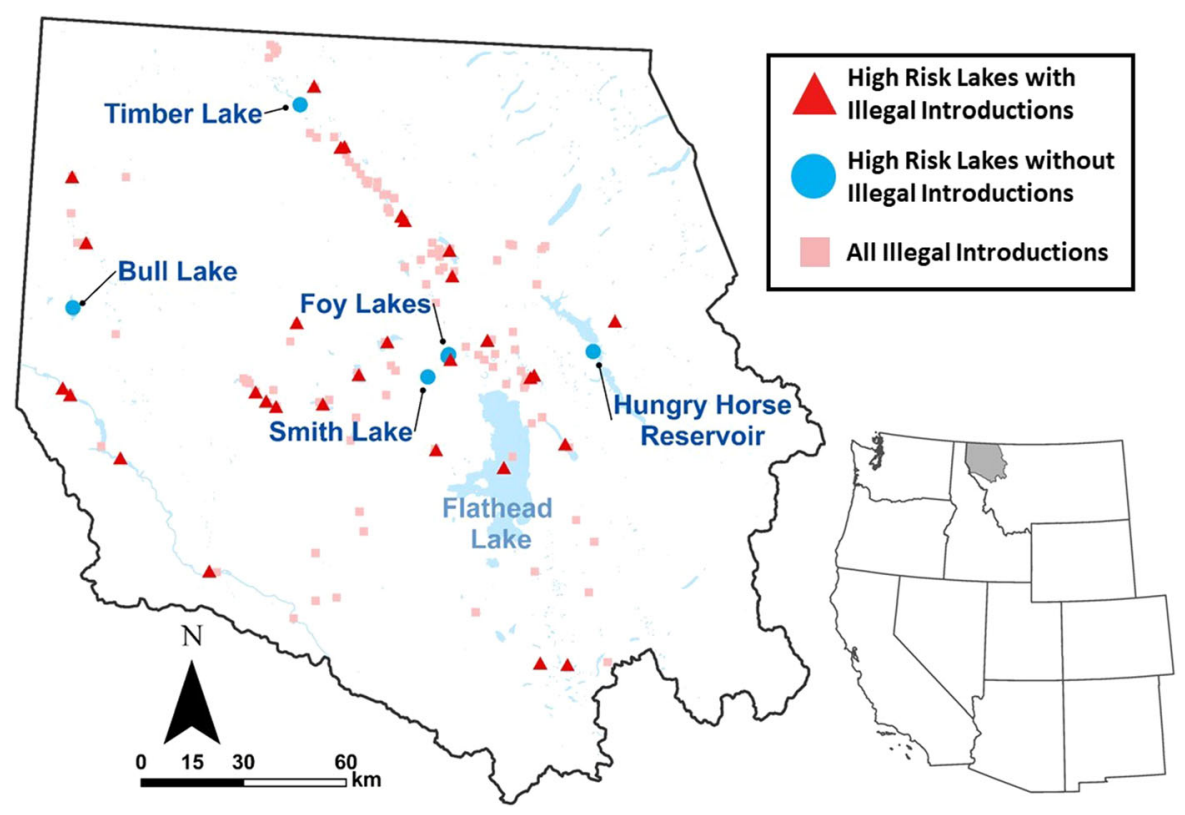

Fig. 1 The location of MFWP Region 1 (R1) within the state of Montana, USA and waterbodies in light blue. Locations of illegal introductions are indicated by the symbols in the key.

forest ecosystem (Fig. 1). There are 947 named waterbodies (lakes, reservoirs, and ponds) in Region 1 , and since 1953, 265 individual illegal fish introductions have occurred in 112 unique waterbodies. Waterbodies with significant portions located in Canada (e.g., Lake Koocanusa, Upper Waterton Lake) were not included in this analysis.

Records of illegal fish introductions in Region 1 have been compiled by MFWP since 1953 and include introductions up to the 2015 Swan Lake Walleye introduction. The accuracy of detecting an illegal fish introduction is influenced by the frequency of fish sampling events in waterbodies and the persistence of the illegally introduced species. Therefore, more illegal fish introductions have likely occurred on the landscape than are reported in our database. We define an illegal fish introduction as a new occurrence of any fish in a waterbody that was not part of an agencysanctioned introduction. Unauthorized fish introductions encompass illegal, inadvertent, and colonization pathways (Rahel \& Smith, 2018), but we believe that the majority of the fish introductions in our dataset are of the illegal nature.

Each entry of an illegal introduction includes what species was introduced, where the introduction occurred, and unique waterbody data including size,
Lakes considered 'High Risk' without previously recorded illegal introductions are labeled. Flathead Lake is labeled for reference

elevation, fishing pressure (angler days), distance to the nearest illegal introduction, distance to a major highway, and human population within a radius of $16 \mathrm{~km}$ (10 miles). We hypothesized that some combination of these variables would correlate with the presence or absence of an illegal fish introduction. These variables were generated using ArcGIS 10.5 with spatial analyst extension. Acreage was calculated based on the shape of the lake feature from USGS Hydro 1:100 K, USGS Hydro 1:24 k, and NAIP imagery. The elevation of each lake was calculated by taking the center point of the feature and intersecting it with the Montana 30-m DEM. Fishing pressure was found through MFWP angling pressure surveys conducted every 2 years in current form since 2005 (see supplementary material for a detailed description of how the angler pressure variable was generated). The distance variables were generated with the near proximity geoprocessing tool. The human population within $16 \mathrm{~km}$ was generated using the Montana cities and town layer maintained by the Montana State Library. The datasets used in this analysis were produced and maintained by MFWP or the Montana State Library. A matching dataset of all Region 1 lakes was combined with the illegal introductions dataset 


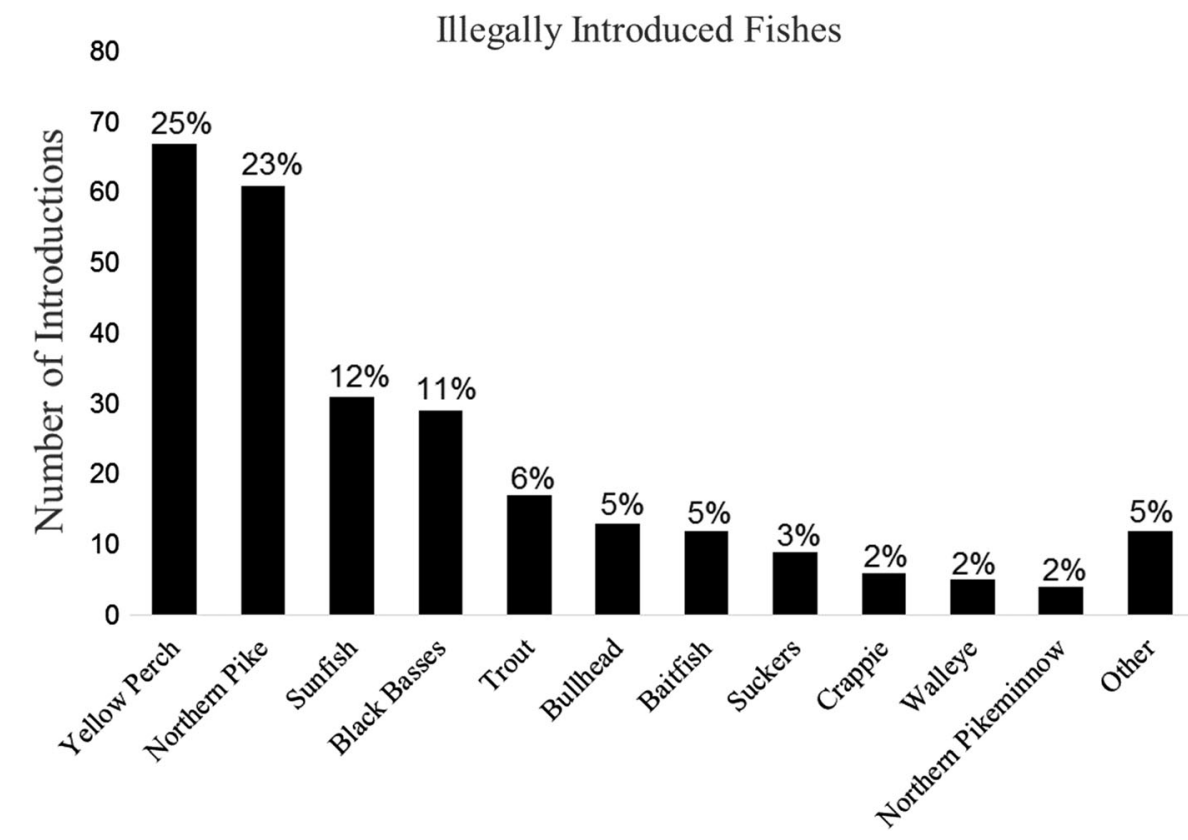

Fig. 2 Illegal introductions in Region 1 of individual taxa that were recorded more than twice. The y-axis is the number of illegal introductions and the percent-of-total shown above each

such that each of the 947 lakes in Region 1 were listed as having had past illegal introductions or none.

\section{Data Analyses}

We first looked at the number of illegal fish introductions that occurred and calculated the percent frequency of all introductions by fish species in Region 1 . The presence/absence of an illegal fish introduction in a waterbody was used as a binary response variable ( 0 or 1) in a logistic regression framework. All subsequent analyses were performed on this binary response data using generalized linear models (GLM; i.e., logistic regression).

First, possible correlation of explanatory variables was assessed with pair-wise regressions of all variables (Peterson \& Carl, 2018) and by calculating variance inflation factors (Supplement 1). The variables lake elevation, lake distance to another illegal introduction, and lake distance to a major highway all showed evidence of correlation (Pearson correlations:

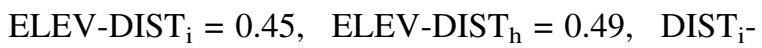
DIST $_{\mathrm{h}}=0.70$; Supplement 1). Subsequent GLMs in which these three variables were interchanged, indicated that AIC values were minimized, and model fit bar. Trout includes Brown Trout, Rainbow Trout, Lake Trout, Brook Trout, Bull Trout, and Bull $\times$ Brook Trout hybrids

maximized by using lake elevation. A candidate set of 23 single and multivariate models with and without variable interactions were tested using an information theoretic approach. We assessed model fit and significance $(\alpha=0.05)$ with AIC scores and tested assumptions regarding overdispersion (Burnham \& Anderson, 2002). For models with a difference in AIC scores less than two points, we chose the most parsimonious to analyze. Additionally, McFadden's pseudo- $R^{2}$ (McFadden, 1977; Signorell 2019) was calculated to assess explanatory power of the regression and a Hosmer-Lemeshow test (Hosmer et al., 2013) was used to evaluate goodness-of-fit (Lele et al. 2019).

Lastly, we calculated an Introduction Vulnerability Index ("vulnerability index", see equation in results section) for each lake in Region 1, using the regression equation to predict if waterbodies with known illegal introductions are at higher risk than those without introductions in our original dataset. Lakes with vulnerability index values greater than zero represent those at higher risk of introduction and were placed in a "High Risk" category. Lakes with a vulnerability index value of less than zero were placed in a "Low Risk" category. 

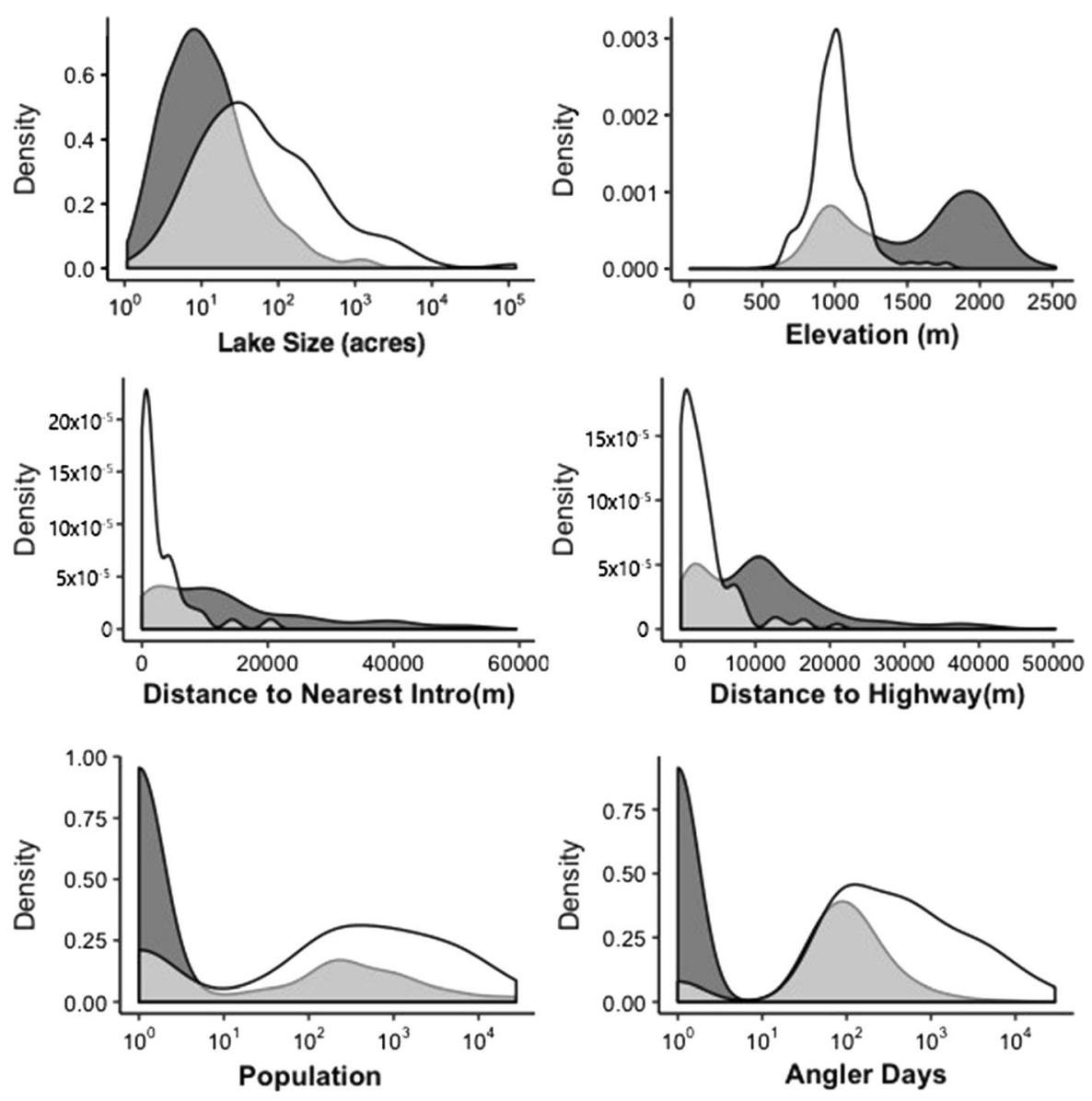

Fig. 3 Density distributions of the six variables for Region 1 lakes with (white) and without (gray) illegal introductions

\section{Results}

Of the 265 illegal fish introductions recorded in Region 1, Yellow Perch $(n=67)$ and Northern Pike $(n=61)$ account for nearly half $(48.3 \%)$. Other groups making up a significant percent of introductions include Lepomis sunfishes (11.7\%), Black Bass (Micropterus spp.), (10.9\%), Salmonids (6.4\%), and baitfish-minnows (Redside Shiner, (Richardsonius balteatus); Fathead Minnow, (Pimephales promelas); and Central Mud Minnow, (Umbra limi); 4.5\%); (Fig. 2). Many of these illegal introductions occurred in or near habitat for native species-of-concern including Westslope Cutthroat Trout (O. c. lewisi), Redband Trout (O. mykiss gairdneri), Bull Trout (Salvelinus confluentus), Deepwater Sculpin (Myoxocephalus thompsonii), Spoonhead Sculpin (Cottus ricei), Torrent Sculpin (Uranidea rhotheus), Pygmy
Whitefish (Prosopium coulteri), and Trout-Perch (Percopsis omiscomaycus).

All six physical and social variables examined showed at least some differentiation between lakes with and without illegal introductions (Fig. 3). The lowest AIC values were obtained using a combination of lake elevation, human population, and fishing pressure (Fig. 4, Table 1), all of which indicated low collinearity (Supplement 1). The best fit equation, outputting an index of the vulnerability of a waterbody to illegal introduction, is as follows:

Introduction Vulnerability Index

$$
\begin{aligned}
& =(1.96-(0.00355[E L E V])-(0.00135[\text { POP }]) \\
& +\left(8.07 \times 10^{-4}[\text { FISH }]\right) \\
& \left.+\left(1.5 \times 10^{-6}[\text { ELEV *POP }]\right)\right)
\end{aligned}
$$




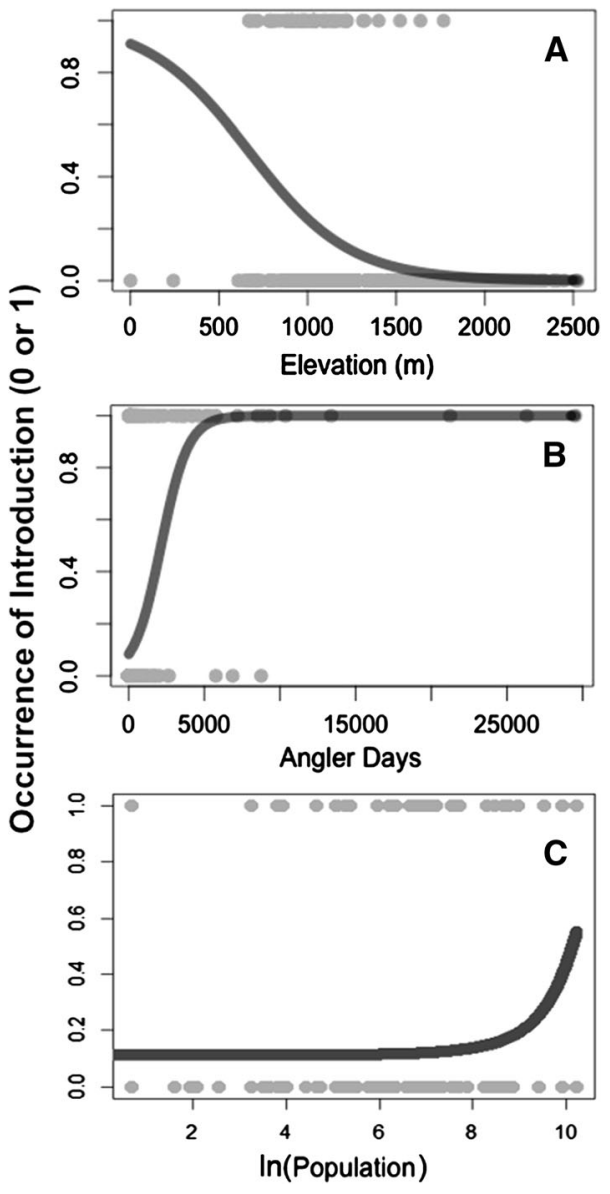

Fig. 4 Single-variable models (dark line) fit to illegal introduction data (gray dots): waterbody elevation (A), fishing pressure $(\mathbf{B})$, and human population within a $16-\mathrm{km}$ radius of a waterbody $(\mathbf{C})$

where $E L E V$ is lake elevation in meters, $P O P$ is the human population within a $16 \mathrm{~km}$ radius of the lake, FISH is lake fishing pressure in angler days per year.

Of lakes placed in the "High Risk" category by the equation (index value $>0), 80 \%(n=24)$ had known illegal introductions and 20\% $(n=7)$ did not (Fig. 5). Goodness-of-fit and pseudo- $\mathrm{R}^{2}$ tests indicated good model fit (Hosmer-Lemeshow test: $\chi^{2}=14.056$, df $=$ $8, P$ value $=0.08031$, where significant $\mathrm{p}$-values indicate poor model fit; $\rho_{\text {McFadden }}^{2}=0.33$ where values between 0.2 and 0.4 are considered "excellent fit."); (McFadden, 1977). The equation placed 853 of the 947 lakes in the correct category (having an introduction or not), representing $90.1 \%$ accuracy.

\section{Discussion}

Using only three variables (elevation, surrounding population, and fishing pressure), our vulnerability equation was able to predict which Region 1 lakes did and did not have past illegal fish introductions with 90\% accuracy (Fig. 5). Lake elevation was the top single variable and likely represents the difficulty for would-be bucket biologists to access high mountain lakes. In one of the few related studies, unauthorized introductions and population expansion of Smallmouth Bass (Micropterus dolomieu) were strongly correlated to the presence of humans, including cottages and lodges, in central Ontario, Canada (Kaufman et al., 2009). Given the complexity of predicting human behavior, we feel the vulnerability equation, coupled with the knowledge of local fisheries personnel, is the best tool to prioritize which northwestern Montana lakes are most at risk for a future illegal introduction. However, the vulnerability equation does not account for which species may be introduced and how a given species assemblage may be affected. It is likely that species-of-concern or economically important sportfishes residing in "High Risk" lakes with previous introductions would still be harmed by further illegal introductions. We therefore suggest preventative measures should be considered for all "High Risk" lakes (Table 2).

The last entry in our database of illegal introductions is from 2015. As evidence of the vulnerability equation's applicability, one of the lakes with the highest vulnerability indexes without past illegal introductions (Bull Lake), has since experienced such introductions (M. Hensler, Montana Fish, Wildlife \& Parks, personal communication). October 2019 surveys in Upper Thompson Lake, another Region 1 lake we categorized as High Risk (Table 2), found two illegally introduced Walleye (MFWP, 2019).

One of the lakes without introductions having a very high vulnerability index is Hungry Horse Reservoir (Fig. 1) and should be the target of preventative action. Hungry Horse Reservoir and the interconnected South Fork Flathead River drainage is largely unimpacted by anthropogenic disturbance because the headwaters of the drainage occur in the Bob Marshall Wilderness Complex. The watershed represents one of the largest interconnected habitats for iconic native fish species including genetically pure Westslope Cutthroat Trout (Liknes \& Graham, 1988; Shepard 
Table 1 A subset of the variable combinations used in GLM models. The lowest AIC values represent the models that best fit the data (gray highlighted section). Models with ELEV had better fit and AIC values than models with $D I S T_{i}$. Models with $D I S T_{i}$ had better fit and AIC values than with $D I S T_{h}$

\begin{tabular}{|c|c|c|c|}
\hline Variables included & Residual deviance & AIC & Significance $(\alpha<0.05)$ \\
\hline ELEV*POP*FISH & 456 on $939 \mathrm{df}$ & 472 & Some variables significant \\
\hline $\mathrm{ELEV}+\mathrm{POP}+\mathrm{FISH}+\mathrm{ELEV}: \mathrm{POP}$ & 462 on $942 \mathrm{df}$ & 472 & All significant \\
\hline SIZE*DIST $_{\mathrm{i}} * \mathrm{POP} * \mathrm{FISH}$ & 448 on $931 \mathrm{df}$ & 480 & Some variables significant \\
\hline ELEV + FISH & 474 on $944 \mathrm{df}$ & 481 & Both significant \\
\hline ELEV*FISH & 474 on $943 \mathrm{df}$ & 482 & ELEV significant \\
\hline $\mathrm{ELEV}+\mathrm{POP}+\mathrm{FISH}$ & 474 on $943 \mathrm{df}$ & 482 & ELEV, FISH significant \\
\hline ELEV*POP & 522 on $943 \mathrm{df}$ & 530 & All significant \\
\hline ELEV & 538 on $945 \mathrm{df}$ & 542 & significant \\
\hline $\mathrm{DIST}_{\mathrm{i}}$ & 548 on 945 & 552 & Significant \\
\hline $\operatorname{DIST}_{\mathrm{h}}$ & 556 on 945 & 560 & Significant \\
\hline FISH & 583 on $945 \mathrm{df}$ & 587 & Significant \\
\hline POP & 672 on $945 \mathrm{df}$ & 676 & Significant \\
\hline SIZE & 679 on $945 \mathrm{df}$ & 683 & Marginally insignificant \\
\hline SIZE*ELEV*POP*FISH & 7281 on $931 \mathrm{df}$ & 7313 & All significant \\
\hline
\end{tabular}

Variables: SIZE (lake size), ELEV (elevation), DISTi (distance-to-nearest introduction), DISTh (distance to maj. Highway), POP (human pop. w/in 10-mi.), FISH (fishing pressure)

+ indicates variables without an interaction, : indicates an interaction, * indicates both

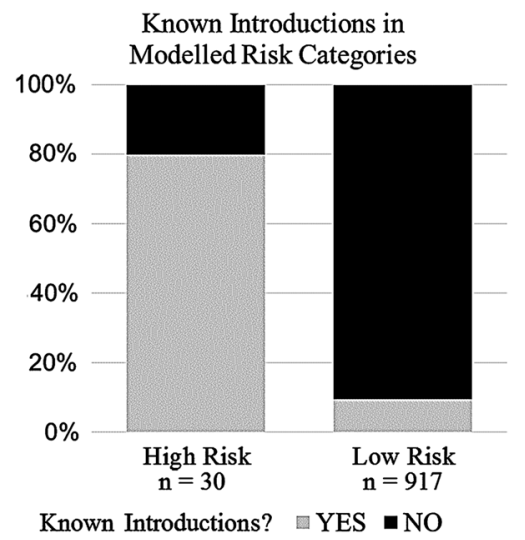

Fig. 5 Lakes placed into "Low" and "High Risk" categories by the Introduction Vulnerability Equation are shown as bar plots. The percent of lakes with known illegal introductions is shown in gray and those without in black

et al., 2005) and Bull Trout (Kovach et al., 2018). Additionally, we propose that preventative measures be first implemented for "High Risk" lakes where healthy populations of sensitive species are found (Table 2).

The majority of illegally introduced fishes in our study were warm or coolwater species, not coldwater species (Fig. 2). The native abundance and history of government-sanctioned salmonid stocking (Johnson et al., 2009) likely explains why trout species make up such a small portion (6.4\%) of these introductions. Preventing the further spread of warmwater fishes is highly important for preserving valuable sport fisheries and native species assemblages (Koel et al., 2005; Carey et al., 2011). For example, Kaufman et al. 2009 found the combined impact of illegally introduced Smallmouth Bass and over-exploitation had detrimental impacts to native Lake Trout populations, prompting government agencies to consider alternative management actions.

Our study addresses the spread of illegal fish introductions through human vectors and therefore does not explicitly consider factors such as propagule pressure, temperature, and habitat that are related to the persistence and spread of introduced species (Jeschke \& Strayer, 2006; Marr et al., 2010). However, examined variables such as waterbody size and elevation do implicitly account for some abiotic and biotic factors for which data were not available. Future research may benefit from the inclusion of other environmental variables that were unavailable for this 
Table 2 Lakes at "High Risk" for illegal fish introductions in Region 1 according to the vulnerability index

The sensitive species found within each waterbody is provided. Lakes above the dividing line have no record of illegal introductions while those below do

BULL Bull Trout, $P W F$

Pygmy Whitefish, WCT

Westslope Cutthroat Trout, $R B$ redband trout

${ }^{\mathrm{a} C}$ Contains Northern Pikepossibly illegally introduced

\begin{tabular}{|c|c|c|c|}
\hline Lake name & County & Vulnerability Index & Species of concern \\
\hline Smith Lake ${ }^{a}$ & Flathead & 565.5 & NONE \\
\hline Bull Lake & Lincoln & 409.6 & BULL, PWF, WCT \\
\hline Hungry Horse Reservoir & Flathead & 401.3 & BULL, PWF, WCT \\
\hline Middle Foy Lake & Flathead & 157.0 & NONE \\
\hline Timber Lake & Lincoln & 82.9 & NONE \\
\hline Lower Foy Lake & Flathead & 73.4 & NONE \\
\hline Flathead Lake & Flathead & 2226.4 & BULL, PWF, WCT \\
\hline Noxon Rapids Reservoir & Sanders & 2007.1 & BULL, WCT \\
\hline Lake Mary Ronan & Lake & 1509.6 & WCT \\
\hline Echo Lake & Flathead & 959.2 & NONE \\
\hline Thompson Lake, Middle & Lincoln & 667.5 & NONE \\
\hline Swan Lake & Lake & 577.6 & BULL, PWF, WCT \\
\hline Whitefish Lake & Flathead & 570.4 & BULL, PWF, WCT \\
\hline Little Bitterroot Lake & Flathead & 556.4 & PWF \\
\hline Cabinet Gorge Reservoir & Sanders & 516.7 & BULL, WCT \\
\hline Foy Lake & Flathead & 439.8 & NONE \\
\hline Blanchard Lake & Flathead & 347.3 & NONE \\
\hline Lower Stillwater Lake & Flathead & 317.4 & WCT \\
\hline Thompson Lake, Lower & Sanders & 241.7 & NONE \\
\hline Dickey Lake & Lincoln & 230.5 & BULL \\
\hline Thompson Falls Reservoir & Sanders & 180.6 & BULL \\
\hline Thompson Lake, Upper & Lincoln & 169.0 & NONE \\
\hline Glen Lake & Lincoln & 135.3 & BULL \\
\hline Savage Lake & Lincoln & 101.1 & WCT \\
\hline Ashley Lake & Flathead & 100.7 & PWF, WCT \\
\hline McWenneger Slough & Flathead & 98.0 & NONE \\
\hline Mcgregor Lake & Flathead & 65.2 & NONE \\
\hline Island lake & Lincoln & 59.8 & NONE \\
\hline Kilbrennan Lake & Lincoln & 49.6 & RB \\
\hline Triangle Pond & Sanders & 32.1 & WCT \\
\hline
\end{tabular}

study such as water temperature and habitat. Interestingly, top social and physical variables in our analysis did not include distance-to-nearest illegal introduction (i.e., spatial autocorrelation) as a major driver of introductions. While "natural" spread of reproducing populations from illegal introductions certainly occurs in northwest Montana, our data suggest a high willingness of "bucket biologists" to transport species long distances (e.g., Bourret \& Clancy, 2018). However, distance-to-nearest introduction is not a static variable like waterbody size or elevation, and changes with increased numbers of introductions. While our data were calculated post hoc and therefore do not account for this change over time, distance was a poor predictor of introductions. However, two of the three waterbodies with more than 10 instances of illegal introduction (Banana Lake and Lion Lake) are near a major highway and the third waterbody (Tetrault Lake) is accessible via a state-operated fishing access site (Supplement 1). All three lakes were placed in the "Low Risk" category by our equation, likely indicating that some measure of accessibility is still an introduce fish, even if not easily captured by the variables included in this analysis. These three lakes are indicative of the fact that different anglers have different priorities. Indeed, while our equation was relatively accurate in determining overall propensity important factor to some anglers wishing to illegally 
for illegal introductions, there were still 88 waterbodies with known illegal introductions that were placed in the "Low Risk" category. This may indicate that illegal introductions are highly idiosyncratic or that some latent social or physical variable, not included in our analysis, drives illegal introductions in these waterbodies.

We recognize that completely stopping all illegal fish introductions is impossible. However, preventative measures such as increased presence of game wardens, educational outreach activities, witness rewards, and signs warning anglers about the legal ramifications of dumping fish, are among the few tools available for deterrence (Rahel \& Smith, 2018). Quantitatively informed decisions about where these measures may be most effective are only possible when agency personnel take the time to record all instances of illegal introductions in a common database. Many authors of scientific studies suggest that biologists collect yet more data (e.g., Murphy \& Noon, 1991), and this study is no exception. But keeping records of introductions takes minimal effort on behalf of local fisheries biologists and consistent curation by individuals within a region may allow for the development of a vulnerability index most applicable to that area. Indeed, Rahel and Smith (2018) were able to create such a database retroactively by collating information from state fisheries reports, peerreviewed articles, university theses, and personal communications from regional biologists. While we do not suggest our specific equation be applied outside of northwestern Montana, we believe this study serves as further example of the utility of this type of data and provides a method by which it can be useful. We used an approach similar to that employed by Marchetti et al. (2004) who used logistic regression to determine what life history traits led some non-native fishes to become established in California waterbodies. However, other techniques may also prove useful for this type of data.

While the role of invasive species in the decline of natives is well documented and understood (Cambray, 2003), both authorized and unauthorized stocking of non-native species remain common. In Montana, for example, at least 5.6 million non-native fishes were legally stocked in 2018 in both artificial and natural stillwaters and at least three streams (Montana Fish, Wildlife \& Parks, 2019). However, potential impacts of such introductions are usually carefully weighed by agency personnel and conducted where non-natives are already naturalized (Rahel, 2004). Unauthorized facilitation of species invasion, on the other hand, is conducted outside established processes, is known to often harm native species, and is becoming an increasingly large pathway by which freshwater ecosystems are altered (Johnson et al., 2009). These alterations can in turn lead to catastrophic changes to ecosystem structure and function (Vitule et al., 2009). Therefore, new tactics and strategies for stemming the tide of continued species invasion must continue to be developed.

Acknowledgements We would like to thank Dr. Kezia Manlove at Utah State University for providing valuable statistical guidance. Jim Vashro, former MFWP Region 1 Fisheries Manager, is largely responsible for compiling the dataset used in this analysis and deserves much of the credit for his vigilance in tracking illegal fish introductions and thanks for comments on the manuscript. Ryan Alger, MFWP GIS/Natural Resource Data Analyst, provided a valuable update to this dataset. Marc Terrazas, Adam Sepulveda, Antti Eloranta, and three anonymous reviewers provided helpful comments.

Data availability Data are freely available and provided as an Excel file and accompanying $\mathrm{R}$ code as supplementary information.

\section{Compliance with ethical standards}

Conflict of interest The authors declare that they have no conflicts of interest.

Open Access This article is licensed under a Creative Commons Attribution 4.0 International License, which permits use, sharing, adaptation, distribution and reproduction in any medium or format, as long as you give appropriate credit to the original author(s) and the source, provide a link to the Creative Commons licence, and indicate if changes were made. The images or other third party material in this article are included in the article's Creative Commons licence, unless indicated otherwise in a credit line to the material. If material is not included in the article's Creative Commons licence and your intended use is not permitted by statutory regulation or exceeds the permitted use, you will need to obtain permission directly from the copyright holder. To view a copy of this licence, visit http://creativecommons.org/licenses/by/4.0/.

\section{References}

Bourret, S. L. \& N. G. Clancy, 2018. Using forensic geochemistry via fish otoliths to investigate an illegal fish introduction. Canadian Journal of Fisheries and Aquatic Sciences 1783: 1-6. 
Burnham, K. P. \& D. R. Anderson, 2002. Model selection and multimodel inference - a practical information-theoretic approach -, 2nd ed. Springer, New York.

Cambray, J. A., 2003. Impact on indigenous species biodiversity caused by the globalization of alien recreational fisheries. Hydrobiologia 500: 217-230.

Carey, M. P., B. L. Sanderson, T. A. Friesen, K. A. Barnas \& J. D. Olden, 2011. Smallmouth bass in the Pacific Northwest: a threat to native species; a benefit for anglers. Reviews in Fisheries Science 19: 305-315.

Courtenay, W. R. \& C. R. Robins, 1975. Exotic organisms: an unsolved complex problem. BioScience 25: 306-313.

Ellis, B. K., J. A. Stanford, D. Goodman, C. P. Stafford, D. L. Gustafson, D. A. Beauchamp, D. W. Chess, J. A. Craft, M. A. Deleray \& B. S. Hansen, 2011. Long-term effects of a trophic cascade in a large lake ecosystem. Proceedings of the National Academy of Sciences of the United States of America 108: 1070-1075.

Elvira, B. \& A. Almodovar, 2001. Freshwater fish introductions in Spain: facts and figures at the beginning of the 21st century. Journal of Fish Biology 59: 323-331.

Engelkes, T. \& N. J. Mills, 2011. A conceptual framework for understanding arthropod predator and parasitoid invasions. BioControl 56: 383-393.

Folke, C., S. Carpenter, B. Walker, M. Scheffer, T. Elmqvist, L. Gunderson \& C. S. Holling, 2004. Regime shifts, resilience, and biodiversity in ecosystem management. Annual Review of Ecology, Evolution and Systematics 35: 557-581.

Gozlan, R. E., 2009. Response by R Gozlan Biodiversity crisis and the introduction of non-native fish: solutions, not scapegoats. Fish and Fisheries 10: 109-110.

Gresswell, R. E., 2011. Biology, status, and management of the yellowstone cutthroat trout. North American Journal of Fisheries Management 31: 782-812.

Hosmer, D. W., S. Lemeshow \& R. X. Sturdivant, 2013. Applied Logistic Regression. Wiley, Hoboken, New Jersey.

Jeschke, J. M., \& D. L. Strayer, 2006. Determinants of vertebrate invasion success in Europe and North America. Global Change Biology 12:

Johnson, B. M., R. Arlinghaus \& P. J. Martinez, 2009. Are we doing all we can to stem the tide of illegal fish stocking? Fisheries 34: 389-394.

Kaufman, S. D., E. Snucins, J. M. Gunn \& W. Selinger, 2009. Impacts of road access on lake trout (Salvelinus namaycush) populations: regional scale effects of overexploitation and the introduction of smallmouth bass (Micropterus dolomieu). Canadian Journal of Fisheries and Aquatic Sciences 66: 212-223.

Koel, T. M., P. E. Bigelow, P. D. Doepke, B. D. Ertel \& D. L. Mahony, 2005. Nonnative lake trout result in Yellowstone cutthroat trout decline and impacts to bears and anglers. Fisheries 30: 10-19.

Kovach, R. P., J. B. Armstrong, D. A. Schmetterling, R. AlChokhachy \& C. C. Muhlfeld, 2018. Long-term population dynamics and conservation risk of migratory bull trout in the upper Columbia River basin. Canadian Journal of Fisheries and Aquatic Sciences 75 (11): 1960-1968.

Lele, S. R., J. L. Keim, \& P. Solymos, 2019. ResourceSelection: Resource selection (probability) functions for use- availability. $\mathrm{R}$ package version $0.3-5$. https://CRAN.Rproject.org/package=ResourceSelection

Leprieur, F., S. Brosse, E. Garcia-Berthou, T. Oberdorff, J. D. Olden \& C. R. Townsend, 2009. Scientific uncertainty and the assessment of risks posed by non-native freshwater fishes. Fish and Fisheries 10: 88-97.

Liknes, G. A. \& P. J. Graham, 1988. Westslope cutthroat trout in Montana: life history, status, and management. In Gresswell, R. E. (ed.), Status and management of cutthroat trout. American Fisheries Society Symposium 4, Bethesda, Maryland, 53-60.

Marchetti, M. P., P. B. Moyle \& R. Levine, 2004. Invasive species profiling? Exploring the characteristics of non-native fishes across invasion stages in California. Freshwater Biology 49: 646-661.

Marr, S. M., M. P. Marchetti, J. D. Olden, E. Garcia-Berthou, D. L. Morgan, I. Arismendi, J. Day, C. L. Griffiths \& P. H. Skeleton, 2010. Freshwater fish introductions in mediterranean-climate regions: are there commonalities in the conservation problem? Diversity and Distributions 16: 606-619.

McFadden, D., 1977. Quantitative methods for analyzing travel behavior of individuals: some recent developments. Institute of Transportation Studies, University of California, Berkeley, California.

McMahon, T. E. \& D. H. Bennett, 1996. Walleye and Northern Pike: boost or bane to northwest fisheries? Fisheries 21: 6-13.

MFWP, 2019. Illegally introduced walleyes discovered in Upper Thompson Lake. Montana Fish, Wildlife \& Parks News Release, October 15, 2019. Kalispell, Montana.

Murphy, D. D. \& B. D. Noon, 1991. Coping with uncertainty in wildlife biology. The Journal of Wildlife Management 55: 773-782.

Peterson, B. G. \& P. Carl, 2018. PerformanceAnalytics: Econometric Tools for Performance and Risk Analysis. R package version 1.5.2. https://CRAN.R-project.org/ package $=$ PerformanceAnalytics

Rahel, F. J., 2004. Unauthorized Fish Introductions: Fisheries Management of the People, for the People, or by the People? American Fisheries Society Symposium 44: 431-443.

Rahel, F. J. \& M. A. Smith, 2018. Pathways of unauthorized fish introductions and types of management responses. Hydrobiologia 2018: 41-56.

Sala, O. E., F. S. Chapin, J. J. Armesto, E. Berlow, J. Bloomfield, R. Dirzo, E. Huber-Sanwald, L. F. Huenneke, R. B. Jackson, A. Kinzig, R. Leemans, D. M. Lodge, H. A. Mooney, M. Oesterheld, N. L. Poff, M. T. Sykes, B. H. Walker, M. Walker \& D. H. Wall, 2000. Global biodiversity scenarios for the year 2100. Science 287: 1770-1774.

Schindler, D. W., 1990. Experimental perturbations of whole lakes as test of hypotheses concerning ecosystem structure and function. Oikos 57: 25-41.

Shepard, B. B., B. E. May \& W. Urie, 2005. Status and conservation of westslope cutthroat trout within the western United States. North American Journal of Fisheries Management 25: 1426-1440.

Signorell, A., et mult. al., 2019. DescTools: Tools for descriptive statistics. R package version 0.99.32. https://cran.rproject.org/package $=$ DescTools 
Simberloff, D., J. L. Martin, P. Genovesi, V. Maris, D. A. Wardle, J. Aronson, F. Courchamp, B. Galil, E. GarciaBerthou, M. Pascal, P. Pysek, R. Sousa, E. Tabacchi \& M. Vila, 2013. Impacts of biological invasions: what's what and the way forward. Trends in Ecology and Evolution 28: 58-66.

Spencer, C. N., B. R. McClelland \& J. A. Stanford, 1991. Shrimp stocking, salmon collapse, and eagle displacement. BioScience 41: 14-21.

Vincent, E. R., 1987. Effects of stocking catchable-size hatchery rainbow trout on two wild trout species in the Madison River and O'Dell Creek, Montana. North American Journal of Fisheries Management 7: 91-105.
Vindstad, O. P. L., T. Schott, S. B. Hagen, J. U. Jepsen, L. Kapari \& R. A. Ims, 2013. How rapidly do invasive birch forest geometrids recruit larval parasitoids? Insights from comparison with a sympatric native geometrid. Biological Invasions 15: 1573-1589.

Vitule, J., C. A. Freire \& D. Simberloff, 2009. Introduction of non-native freshwater fish can certainly be bad. Fish and Fisheries 10: 98-108.

Publisher's Note Springer Nature remains neutral with regard to jurisdictional claims in published maps and institutional affiliations. 